On agency and affiliation in second assessments : German and Swedish opinion verbs in talk-in-interaction

\author{
Auer, Peter \\ John Benjamins \\ 2021
}

Auer , P \& Lindström , J 2021, On agency and affiliation in second assessments : German and Swedish opinion verbs in talk-in-interaction . in J Lindström , R Laury , A Peräkylä \& M-L Sorjonen (eds), Intersubjectivity in Action : Studies in language and social interaction .

Pragmatics and Beyond New Series , vol. 326 , John Benjamins , Amsterdam , pp. 81-107 . https://doi.org/10.1075/p

http://hdl.handle.net/10138/339437

https://doi.org/10.1075/pbns.326.05aue

unspecified

submittedVersion

Downloaded from Helda, University of Helsinki institutional repository.

This is an electronic reprint of the original article.

This reprint may differ from the original in pagination and typographic detail.

Please cite the original version. 


\section{On agency and affiliation in second assessments}

\section{German and Swedish opinion verbs in talk-in-interaction}

Peter Auer \& Jan Lindström

\section{Introduction}

German and Swedish have specific "opinion verbs" that are frequently used to convey the speaker's subjective stance to the assessable, as in ich find(e) das gut and jag tycker den är bra. Both can be translated with think in English (i.e. 'I think it is good'), but the English verb has a wider meaning, as it can express opinion or doubt, thus generally flagging uncertain knowledge (see Mullan 2010, p. 51). We will investigate the use of constructions containing the German and Swedish opinion verbs finden and tycka in assessment sequences in conversation, with a special focus on their use in second assessments, building on an elaborating prior work on English second assessments (such as Thompson et al. 2015). The verbs under scrutiny allow the speaker to produce an assessment that is not presented as factual, but rather as expressing his or her opinions, feelings and tastes; hence, the verbs take part in those interactional processes that lead from subjectivity to intersubjectivity. We will analyse utterances framed with ich finde and jag tycker in terms of speakers' agency and affiliation. Both are interactionally intricate for the second assessor. In second position the possibility to say something independently of the speaker in the first position - and hence agency - is restricted (Enfield, 2011), and there is a general preference for expressing agreement (Pomerantz, 1984), i.e., for affiliation. We will argue that speakers of German and Swedish can signal lower agency in second assessments using reduced formats of these verbal constructions when compared to full formats, which in their turn signal higher agency.

The constructional schemata for reduced and full clausal formats with finden and tycka are somewhat different in German and Swedish, respectively. For a quick reference, we have summarized the basic reduced and full constructional configurations in Table 1.

Table 1. Reduced and full clausal formats for finden and tycka in second assessments (EVAL-T = evaluative term, e.g. gut 'good')

\begin{tabular}{l|l|l} 
Clausal format & German (finden) & Swedish (tycka) \\
\hline Reduced & (ja) (das) find ich auch & (ja) $($ det $)$ tycker jag (med/också) \\
& (ja) ich find (das) auch & (ja) jag tycker det (också) \\
& (ja) ich auch & (ja) jag med/också \\
& '(yes) I think so too' & '(yes) I think so (too)' \\
\hline Full & (ja) (das) find ich (auch) EVAL-T & (ja) (det) tycker jag med/också e EVAL-T \\
& (ja) ich finde das (auch) EVAL-T & (ja) jag tycker (också) (att) det e EVAL-T \\
& 'I find that also EVAL-T' & 'I think (that) it is EVAL-T'
\end{tabular}

The reduced format is in both languages mono-clausal and the assessing term is expressed by an anaphoric pronoun (das, det) only, which refers back to the evaluative term used in the first assessment. This pronoun can be lacking in clause-initial position (resulting in so-called topic drop; see Mörnsjö, 2002 on Swedish; Trutkowski, 2016 on German). The turn is usually prefaced by an affirming particle $(j a)$. The reduced construction usually contains a focus adverb (auch, med/ocks ${ }^{\circ}$ ) which is obligatory in German and marks the assessment's "secondness", but also underlines that the speaker subscribes to the term used by the first assessor. When the second assessor disagrees, a negating adverb enters into the construction, for example, (das) find ich nicht, (det) tycker inte jag 'I don't think so'. The full format incorporates a specific evaluative term (for example, gut, bra 'good'). Here, the languages 
differ: the construction is mono-clausal in German, with the assessing term linked to the verb as a predicative adjective, ${ }^{1}$ but it is bi-clausal in Swedish, where the opinion verb in the matrix clause governs a complement clause containing the evaluative term.

We will show that it is consequential for the subsequent sequential trajectory whether the second assessor signals lower or higher agency, as reflected by the reduced vs. full formats of the second assessing turn. In the case lower agency, sequence closure is likely, whereas in the case of the higher agency, the assessing sequence is likely to continue. Another dimension that has a bearing on the sequential development after the second assessment is evaluative (non-)affiliation: when the second assessment is (moderately) downgraded, sequence closure is likely, but when the second assessment is on the same level as the first one, or even upgraded, sequence expansion is likely to ensue, for instance by further assessments. When the second assessor disagrees with the first, the turn or sequence is mostly expanded by an account, irrespective of whether the second assessment uses a full or reduced opinion verb format. These systematic bearings on sequential trajectory, we argue, depend on the speakers" deploying of actions in a "typical" way that then occasions "typical" next actions (see Schuetz 1953, p. 17-20). That is, a certain established response form (e.g. a formally reduced second assessment) is for the speakers of a language recognizable as a form that is likely to project a certain kind of sequential trajectory in interaction (e.g. sequence closure). To rephrase this in Schuetz's (1953, p. 26) terms, the more standardized the prevailing action pattern is, the greater is the chance of success of intersubjective behavior.

The German data come from a variety of conversational encounters - from informal meetings between students (corpus ZK, 10 recordings, appr. 120000 words) to group and dyadic encounters in the first season of German "Big Brother" (corpus BB, 44 recordings, appr. 235000 words), and including telephone conversations from the CALL HOME corpus (97 recordings, appr. 205000 words - and interviews (corpus DiALEKTINTONATION, 124 recordings, appr. 1,2 mio words). The participants cover different age ranges and were all proficient L1 speakers of German. The transcription follows GAT2 (see Selting et al., 2009). The Swedish data consists of a corpus (GSM) of pre-arranged but unscripted sociolinguistic group interviews recorded among high school students in Western Sweden (Norrby \& Wirdenäs, 1998). The speakers are thus in their late teens and proficient L1 speakers of Swedish, although some of them have an immigrant family background. The participants' task was to discuss, describe and assess ten different music samples representing different styles. The total number of recordings is 27 , amounting to 20 hours and about 200000 words. Each interview situation includes a moderator and three to five students. The general atmosphere of the interviews is that of a relaxed conversational interaction and the participants freely argue and take own initiatives in developing the topics. The transcription follows general CA conventions (see Ochs et al., 1996, Appendix).

After discussing some recent contributions to the study of the organization of assessment sequences in general (section 2), we will first show that the speech genre has an impact on the way in which (second) assessments are done in interaction. The genre-specific structural-sequential differences can be fruitfully analyzed with reference to the notion of agency, as we will show in section 3 on the basis of the Swedish data. In section 4, we will present our main argument on the basis of the German data, i.e. that the structure of the assessment sequences is responsive to agency and strength of evaluative affiliation in the second sequential position, which are coded in the linguistic format of the responsive assessments. While this holds for agreeing seconds, section 5 will deal with disagreeing second assessments, using Swedish data; these sequences are always expanded and their

\footnotetext{
${ }^{1}$ German also uses the opinion verb finden as a matrix verb (as in: ich finde, wir sollten jetzt gehen 'I think we should go now'), but this construction is not used in assessments and will therefore not be included in our analysis.
} 
occurrence genre related. The chapter ends with a conclusion where we summarize and reflect on the results.

Our study is located within the framework of Interactional Linguistics (Couper-Kuhlen $\&$ Selting, 2018) and therefore seeks to understand how the deployment of linguistic structure is both situated in talk-in-interaction and shaped by this environment. Given the close structural-functional similarity between Swedish and German opinion verb constructions, we are less interested here in the different interactional resources the two languages offer their speakers but in the ways in which sequential and genre-related contexts shape their use, which also makes our argument potentially applicable to other languages

\section{Agency and affiliation}

Responses to assessments differ according to whether the assessable is known to both participants or only to the assessor (epistemic dimension). Here, we will only be concerned with the first case. Second assessments are also sensitive to the question of whether the assessable is the second speaker or some person or object closely associated with this speaker (in which case a positive first assessment is heard as a compliment), and whether the assessable is the first speaker or some person or object closely associated with this speaker (in which case a positive first assessment is heard as self-praise). Second assessments after these first assessments follow a preference system for agreementwhich means that. among the various possibilities of formulating an agreeing second, seconds in which the speaker affiliates with the first assessor are preferred. Affiliating second assessments are on the same evaluative level as the first, or above ("upgrading") (cf. Pomerantz, 1984; for German also Auer \& Uhmann, 1982).

Disagreeing with the first assessment is a delicate, potentially face-threatening act which is therefore handled with circumspection. As Pomerantz (1984) has shown, the preference for agreement includes the systematic employment of resources that foreshadow disagreement without marking it overtly. This can be achieved by delayed seconds and/or by disagreement-implicative turn-initial particles such as German naja or Swedish nå and nåja ('well'). When introduced by these techniques, seconds that downgrade the first assessment may be heard as disagreement-implicative.

Heritage and Raymond (2005) point out that first and second assessors have ways of weakening and strengthening the epistemic grounds of their assessments. The opinion verbs we are focusing on in this chapter count among the ways speakers have at their disposal to downgrade their epistemic stance, be it in first or second position. By framing the assessment as a subjective opinion, the speaker at the same time refrains from presenting the facts that led to this assessment as objectively compelling. ${ }^{2}$ But Heritage and Raymond also show that second assessments can be more or less independent from the preceding first assessments. By presenting the second assessment as based on an opinion they have always held (hence by strengthening its epistemic grounds), second speakers can claim that they were not only led to share the first speakers' opinion 'in situ', after having heard the first assessment. Inversely, the second assessor may choose to link the second assessment to the first assessment in a way that displays its epistemic dependency on it; in this case, the speaker does not claim to have been of this particular opinion before, or to have ever thought of the matter.

Enfield (2011, p. 308) reframes this difference as one of agency, starting from the observation that the speaker's epistemic position alone does not account for his or her rights to make an assessment in a given sequential slot. First speakers usually make an "independent claim of relevance"; they decided to say what they say exactly at this moment. They are both

\footnotetext{
${ }^{2}$ However, there may be cultural differences in how opinions and facts are oriented to and expressed in discourse (see e.g. Mullan 2010 for differences between French and Australian English).
} 
responsible for and "committed" to (Thompson, Fox \& Couper-Kuhlen, 2015, p. 147-148) what they say more than the second, responding speakers. Second assessors are in a position of weaker agency. For them, there is a danger of being heard as 'saying $\mathrm{x}$ because $\mathrm{Y}$ said $\mathrm{z}$ before'. They may accept their lower agency, and formulate second assessments such that they can be heard as being formulated in such a position; this is linguistically expressed by analeptic formats that make use of the previous utterance as a resource ("reduced formats", see above; cf. Auer 2014). On the other hand, second speakers can also contest the lower agency implied by the second position by choosing a format that can be heard as an independent assessment, i.e. one which does not show any structural orientation to, or reliance on, the format of the previous utterance (the "full formats" mentioned above).

A synthesis of Heritage and Raymond's and Enfield's approach is offered by Thompson, Fox and Couper-Kuhlen (2015, Ch. 4) in their analysis of second assessments. They investigate second assessments in a range of grammatical formats, ranging from simple phrasal assessments (which repeat some lexical material from the first assessment and are highly "parasitic" on it), to "minimal clausal assessments" consisting of a copula and a pronoun, such as it is), "expanded clausal" assessments in which an evaluative term from the first assessment is reused, and "graded clausal" assessments in which the evaluation of the first assessment is upgraded by lexical, prosodic or grammatical means. They argue that these formats can be ordered with respect to (increasing) agency claims by the speaker. The opinion verb constructions that are the focus of this study can be located on this continuum. We will argue that they have sequential implications that have not been described so far and that these implications are in turn reflecting the interactional genre at hand.

We will show that the choice between a reduced and a full syntactic format for the second assessment corresponds with different agency constellations. The more the format is reduced, the more it depends on the structure of the first assessment. In this case, the second assessment implies a lower agency on the part of the second speaker, which is not only a consequence of the responsive sequential position but also of the "tying" of the second to the first assessment format. Sequentiality and grammatical format concur in a strongly asymmetrical agency constellation. Inversely, the choice of a full format for the second assessment counteracts and hence mitigates the sequentially lower agency of the second assessor: the second speaker, although required to produce a second assessment, challenges this position by formulating the assessment in an independent way, i.e. in a format that could also be employed to formulate a first assessment.

These differences have a bearing for the sequential unfolding of interaction. We will show that in a strongly asymmetrical agency constellation, the sequence tends to be closed after the second assessment, i.e. there is "not much more to say" about the matter at hand. On the other hand, when the sequence is more symmetrical in terms of agency, expansion of the sequence is likely. In addition to agency, affiliation also has an impact on the subsequent sequential development: a downgraded second assessment (displaying low affiliation) can close the sequence, while an upgraded second assessment (displaying high affiliation) will often expand it.

The two dimensions of agency and affiliation are not fully independent. A reduced grammatical format (indicating low agency) also encodes low affiliation (imbalance of commitment, see Thompson et al. 2015, p. 155). The opposite is not true, however. A second assessment which is done in a full syntactic format (high agency) can contain an assessment term that upgrades or downgrades the first assessment, thereby displaying higher or lower affiliation.

\section{Dealing with weak agency - assessing in group interviews}


There are speech genres in which the speakers' agency in the formulation of second assessments is constrained while at the same time the genre requires the participants to express their opinions in a rich and elaborate way. Among them are round table or classroom discussions where the participants are asked one after the other to state their opinions on a theme. In such genres, it is the first assessor who has the primary edge to say something independently, whereas the subsequent speakers find themselves struggling to add something original and different from this first speaker (cf. Enfield, 2011). Of course, the second (and all subsequent) assessors may accept their limited agency by simply concurring with the first assessor. Yet, this is not in line with the "rules of the game", which encourages them to state their opinion explicitly and individually.

A typical example of assessing practices in such a genre is presented in extract (1), from the Swedish group interview data. The interviewer invites the interviewees to describe and assess different music pieces and performers. In this case, the Swedish band Kent is at issue. The interviewer (Int) asks in line 01 whether the participants like the band and the song they just have heard (using the phrasal verb tycka om 'like'). Lars responds with a positive first assessment using an opinion verb in a full bi-clausal format (ja tycker de e: bra 'I think it's good'). The second assessor Ted ties his assessment back to this first assessment with an affirming particle (a:) and through thereduced opinion verb format (line 3). This tying is done with an anaphoric pronoun (de 'that') and the additive adverb ocksa 'also, too'. (We mark the first assessment with ' $1 \rightarrow$ ' and the second assessment with ' $2 \rightarrow$.' $)^{3}$

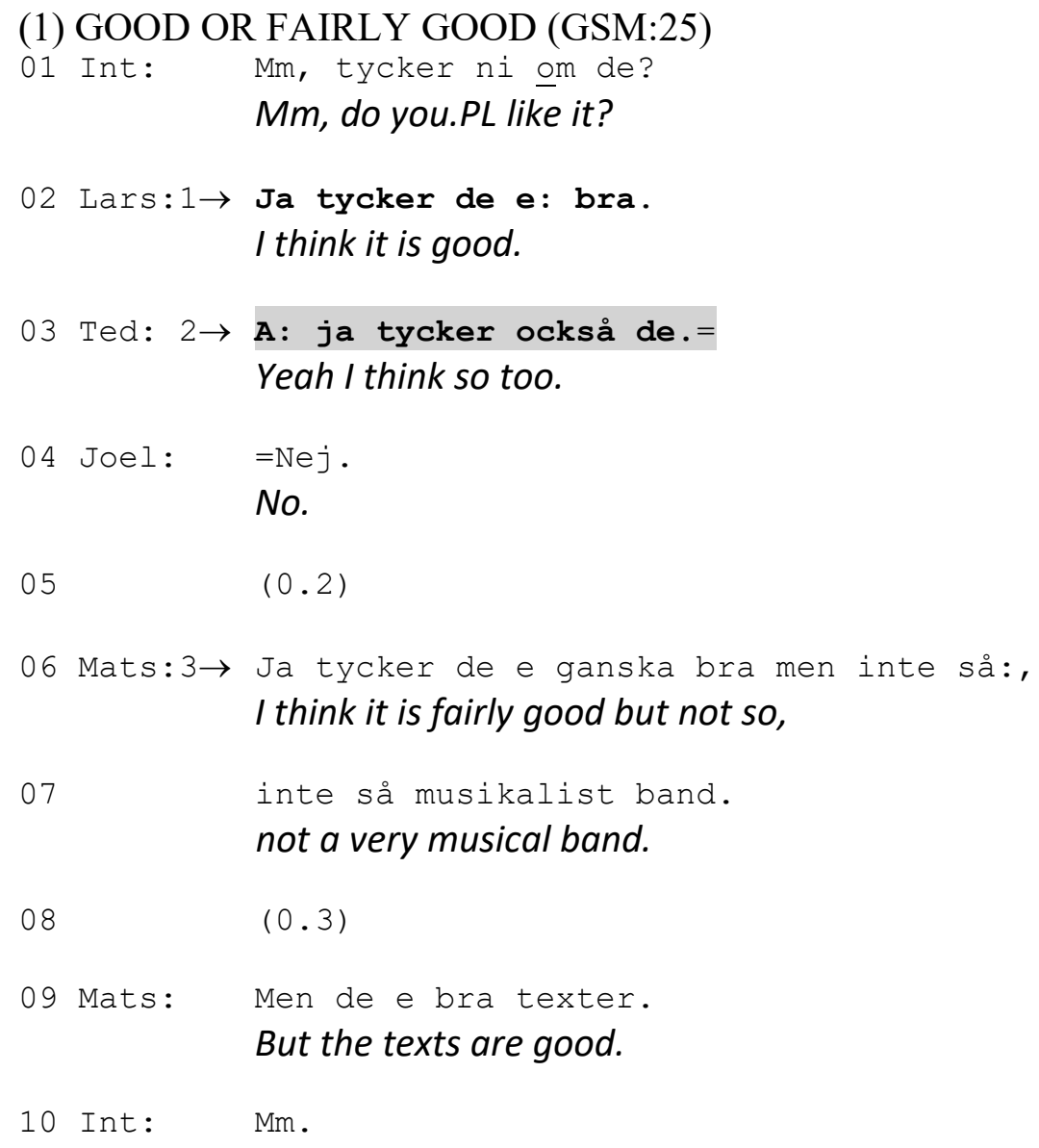

Joel's subsequent negation nej 'no' in line 04 seems to contradict the two previous assessments, but may also be heard as a direct but delayed response to the interviewer's initial

\footnotetext{
${ }^{3}$ This notation follows Ogden (2006) and Thompson, Fox and Couper-Kuhlen (2015).
} 
question. In line 06 , following a short pause, a third assessor Mats comes in, taking a moderately disagreeing position. He uses the full bi-clausal opinion verb format to downgrade his assessment (ganska bra 'fairly good') and adds an elaboration framed with the contrast marker men 'but' in which he further distances himself from the prior positive assessments. Finally, after a pause in line 08, the speaker produces a concessive move (cf. Couper-Kuhlen $\&$ Thompson 2000) that evaluates a part of the assessable in positive terms (the texts are good, rather than the music), thus mitigating the preceding disaffiliating move. The interviewer then treats the sequence - that has contained low-agentive (1.3) and downgrading (1. 6) responsive assessments - as closed by producing the acceptance token $\mathrm{mm}$ in line 10.

Extract (1) shows how first and second (and subsequent) speakers can deploy the Swedish opinion verb tycka in a bi-clausal or mono-clausal constructional format. The former format enables the speaker to formulate an independent assessment in a complement clause [COMP], whereas the latter format ties back the turn to the prior one by the use of an anaphoric pronoun [APRO] that substitutes for an independently formulated assessment. Such "dependent" opinions are further marked as responsive with the adverb ocksa 'also, too':

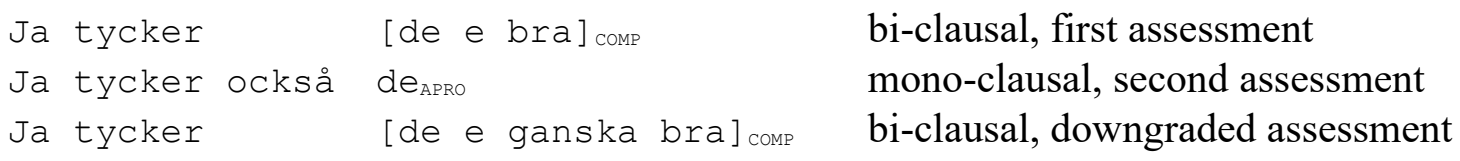

But even when using the mono-clausal format in second position, speakers can resist the implications of low agency by certain means. In the following extract (2) the interviewees are discussing a song by the Swedish singer-songwriter Lisa Ekdahl. After Erik has defined the musical genre in line 01, Anna agrees and delivers a clausal assessment (den e bra 'it's good', 1. 04), which is subsequently reframed as a subjective opinion by the turn-final stance marker tycker ja 'I think', working here as a hedge (see Auer \& Lindström, 2016; cf. Heritage \& Raymond 2005).

(2) KINDA UNUSUAL (GSM:4)

01 Erik: Vispop typ.

Singer-songwriter pop sort of.

02 Anna: Mm.

$03 \quad(0.3)$

$04 \quad 1 \rightarrow$ Den e bra tycker ja. It is good I think.

05 Erik:2 $\rightarrow$ A: tycker ja me faktist, (.) fö de e ovanlit änna. Yeah I think so too actually, (.) because it is kinda unusual.

06 Anna: Mm.=

07 Peter: $=\mathrm{M}: \mathrm{m}$.

08 Erik: Plus att de nog e nånting som (.) alla (.)

And it is probably something that (.) everybody (.) 
Erik responds with an affirming particle $(a$ : $)$ and a concurring assessment in a mono-clausal, reduced opinion verb format; in the clausal unit tycker ja me 'I think so too' the initial (fronted) anaphoric de 'that' is lacking ("topic drop"), which istypical of responsive utterances (see Lindström \& Karlsson, 2005). The responsiveness of this agreement is further marked by the additive adverbial particle $m e(d)$ 'with, too':

[Den e bra] [tycker ja] $]_{\text {Stance }}$

[ ] Tycker ja me faktist

The 'low agency' format of Erik's responsive assessment is however expanded by the final adverb faktist 'actually, in fact'. This adverb marks the opinion expressed here as a move that runs counter to some sequential expectations (cf. Clift, 2001 on Engl. actually). Erik has had a chance to make a first assessment in line 01 where he labels the genre as vispop 'singersongwriter pop', which is not clearly positive or negative. Faktist strengthens the second assessment's independence, suggesting that Erik does not simply go along with the preceding speaker but is committed to an opinion of his own that has relevance (indeed, "facticity") independent of what prior talk and the sequential position prompt him to do (see Schegloff, 1996, p. 63 on Engl. in fact); i.e. Erik makes a contribution that is informative beyond a standard second position agreement. Erik then accounts for his claim of independence by ending the turn with a motivation of his positive assessment ( fö de e ovanlit änna 'because it's kinda unusual') and some further talk on the topic. In other words, measures taken to claim higher agency and independence in second position are, as expected, followed by an expanded turn and sequence.

Balancing between agreement in a responsive position as the preferred option, and claiming agency for the expression of one's own opinion, is a delicate issue; syntactic, lexical and turn-organizational choices play a role in it. In Swedish, reduced (mono-clausal) opinion verb constructions tie the second assessment to the first just by a pronominal "copy", and/or an additive particle. Such responsive formats signal low speaker agency and low commitment to the evaluative term, even though the second speaker affiliates with the first. But second assessors can also contest the weaker agency implied by their sequential position through the use of lexical markers that present this second assessment as an independent opinion, e.g. with faktist 'actually'. They may also (and additionally) provide an account that enables the speakers to say more about the assessable in their own words. Bi-clausal (full) opinion verb constructions, as in line 06 in (1), are another (syntactic) way for subsequent speakers to claim heightened agency. But saying something independentlyalso means a less symmetrical commitment to the evaluative term that the first speaker has proposed, which in turn can create trouble in interaction (see Thompson et al. 2015, p. 180).

\section{Agency, alignment and sequence structure in agreeing second assessments}

In this section, we will show on the basis of German conversational data that a low affiliation and low agency in second assessments are followed by sequence closure, while symmetry or an increase results in sequence expansion. The sequence expansion may take the form of a third assessment, an elaboration giving details of the assessable, or other ways of strengthening affiliation between the speakers. We will go through the various possibilities step by step.

\subsection{Sequence closure: low agency and low affiliation}


After low agency and low affiliation, the sequence tends to be closed. Consider the following example: ${ }^{4}$

(3) NAMES FOR CHICKENS (BB)

((Kerstin's and Manuela's chickens have been given names by other people via postcards sent to them.))

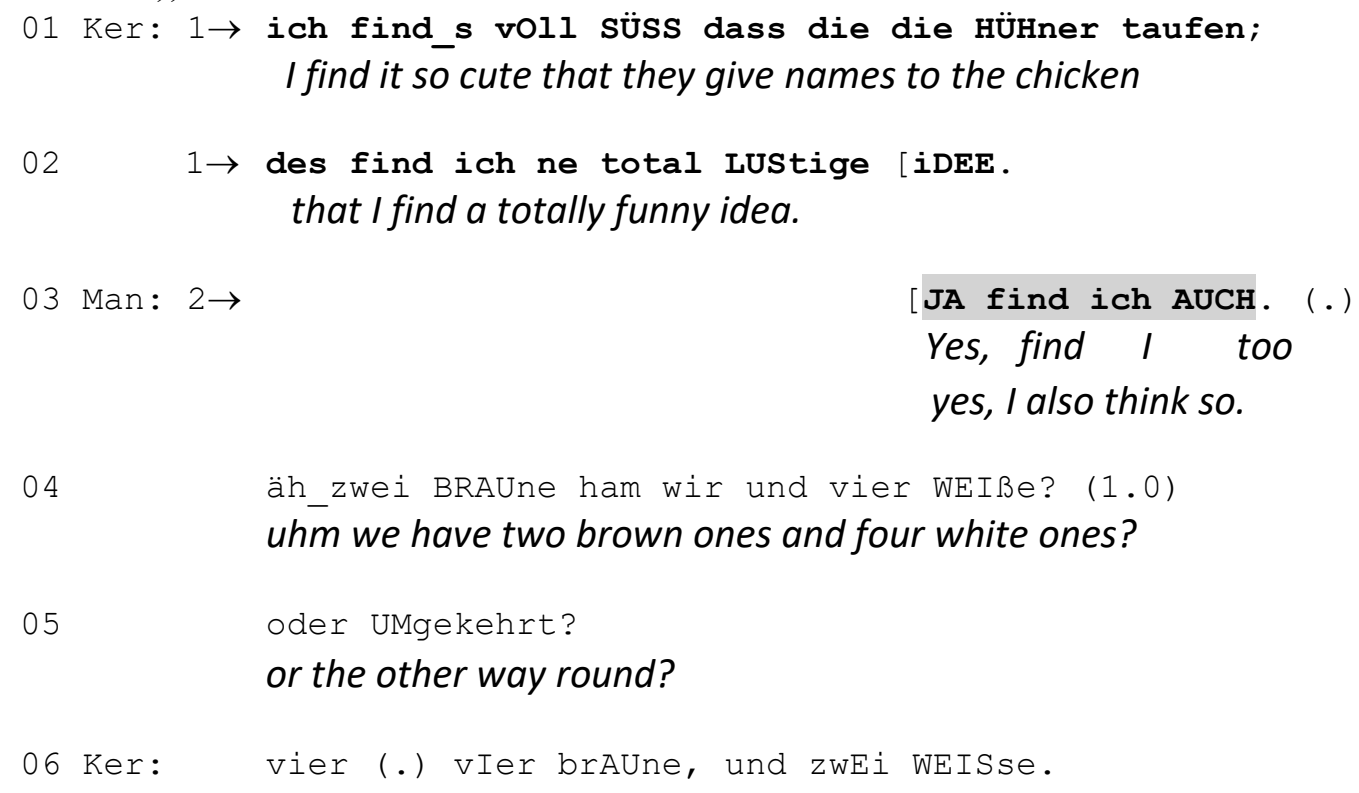

Kerstin produces two assessments in her turn in lines 01-02. Both use the opinion verb finden, which marks the assessment as subjective. The evaluative expressions used for the two assessments are strongly positiv: voll süss (lit. 'fully cute') and total lustig ('totally funny'). The initial assessment (01) precedes the assessable, which is the proposition 'they gave names to the chickens'. The subsequent assessment (02) resumes reference to this proposition by the initial anaphoric pronoun das.

After this rather emphatic first assessment by Kerstin, Manuela's second assessment displays low affiliation. It is introduced by a confirmation token $(j a)$ produced in terminal overlap with Kerstin's last assessment. Syntactically, Manuela employs an analeptic (reduced) finden-construction, which is parasitically (Auer, 2015) built on the previous construction :

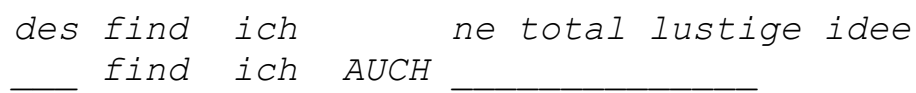

It is the adverb auch ('too') which "imports" the positive evaluative term into the responsive turn. The anaphoric pronoun in topic position is lacking (topic drop). Hence, both in terms of sequence (responsive second assessment) and in terms of syntactic structure, the second assessment is low in agency. This low agency together with low affiliation brings the sequence to a closure: the next comoponent of Manuela's turn does not expand the sequence any further. Moving away from the assessment of the names given to the chicken, Manuela and Kerstin now talk about the chickens' color.

A similar trajectory can be observed in the following extract:

\section{(4) BANGKOK (ZK)}

\footnotetext{
${ }^{4}$ The translations sometimes try to reflect German word order even though the English rendition is only marginally acceptable.
} 


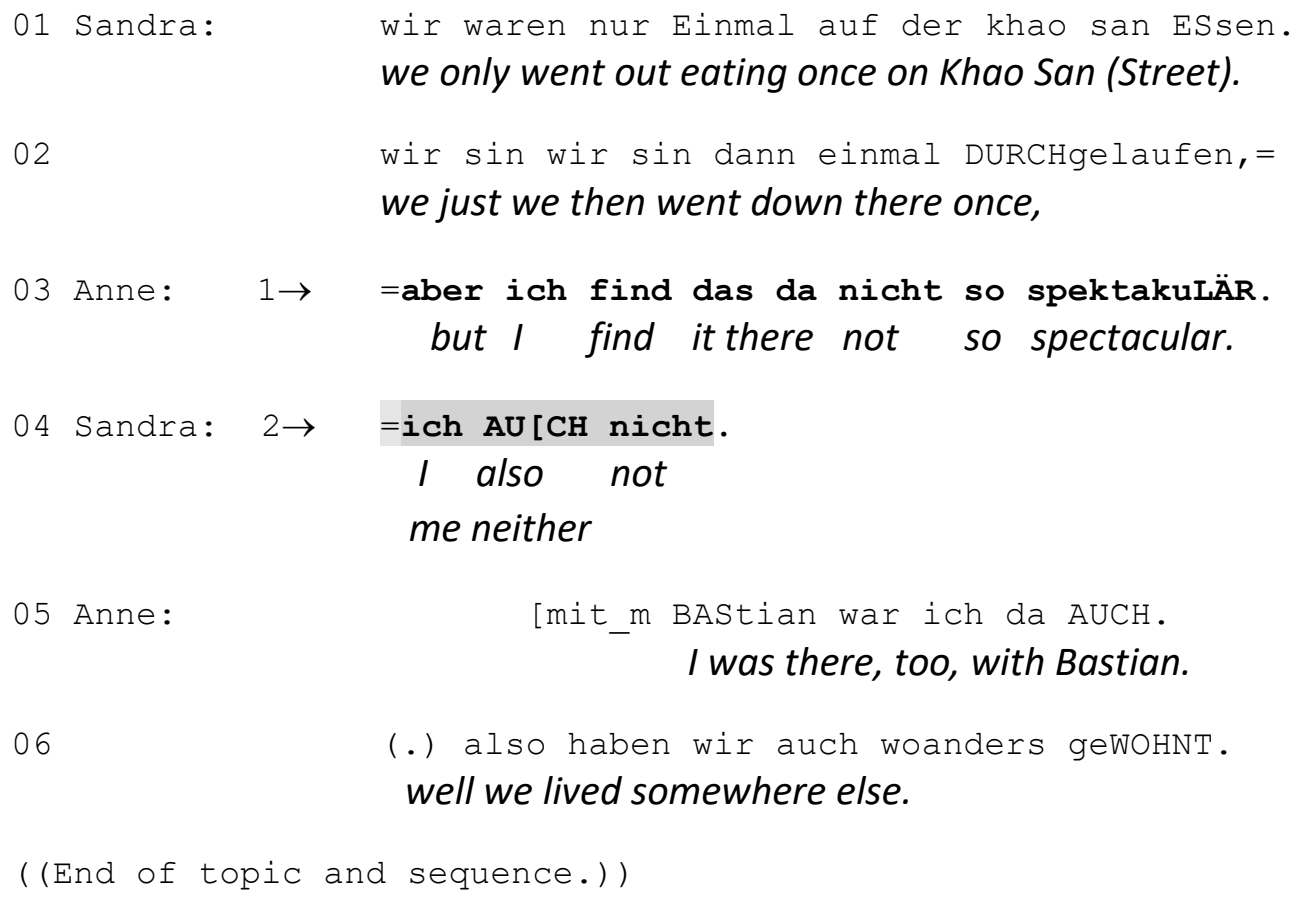

The two young women both visited Bangkok and exchange their views on the city. Sandra's way of introducing Bangkok's Khao San Avenue in lines 01-02 already suggests that this was not the main attraction for her. However, it is Anne who first produces an explicit assessment, displaying her own first-hand epistemic authority. She uses the finden-format which marks the assessment as subjective, and a mildly negative evaluative expression (negating the positive adjective spektakulär). Anne can be heard to expand her turn in line 05 with an account of why she and her boyfried didn't find Khao San Avenue particularly 'spectacular'. But before she can do so, Sandra (somewhat expectably) agrees with this negative assessment in 04. She uses a highly reduced format to do so; not only is the evaluative adjective lacking (as in ex. 3 ), but even the opinion verb is not formulated explicitly but 'imported' from the first assessment by analepsis. The way in which the second assessment builds on the syntax of the first is therefore quite radical:

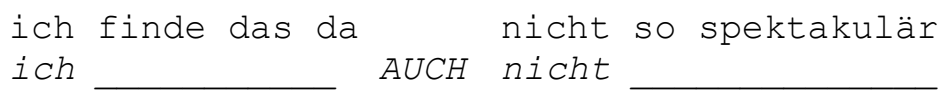

Again, it is the adverb auch that ties the second to the first assessment. Due to the reduced grammatical format, Sandra also expresses low affiliation with Anne. Through low agency and low affiliation of this second assessment, Sandra suggests to close down the sequence. Anne subsequently shifts the direction of her turn from a potential account (perhaps starting in 1. 05) to a comment on where she and her boyfriend stayed in Bangkok, perhaps implying that the distance from this avenue also reduced the possibilities to go there often. This closes the sequence (and the topic).

\subsection{Sequence closure: high(er) agency and low alignment}

There are also cases in our corpus in which the second participant uses a full format for the second assessment, but still the sequence ends after the second assessment. In these cases, the full assessment format contains an evaluative term that downgrades the first assessment, which alone is enough to close down the sequence.

In the following extract, Bibi is talking about a new-born baby (possibly her grandchild and Alma's niece), asking her daughter Alma whether she knows the baby's name: 
(5) BABYNAME (Calling Home)

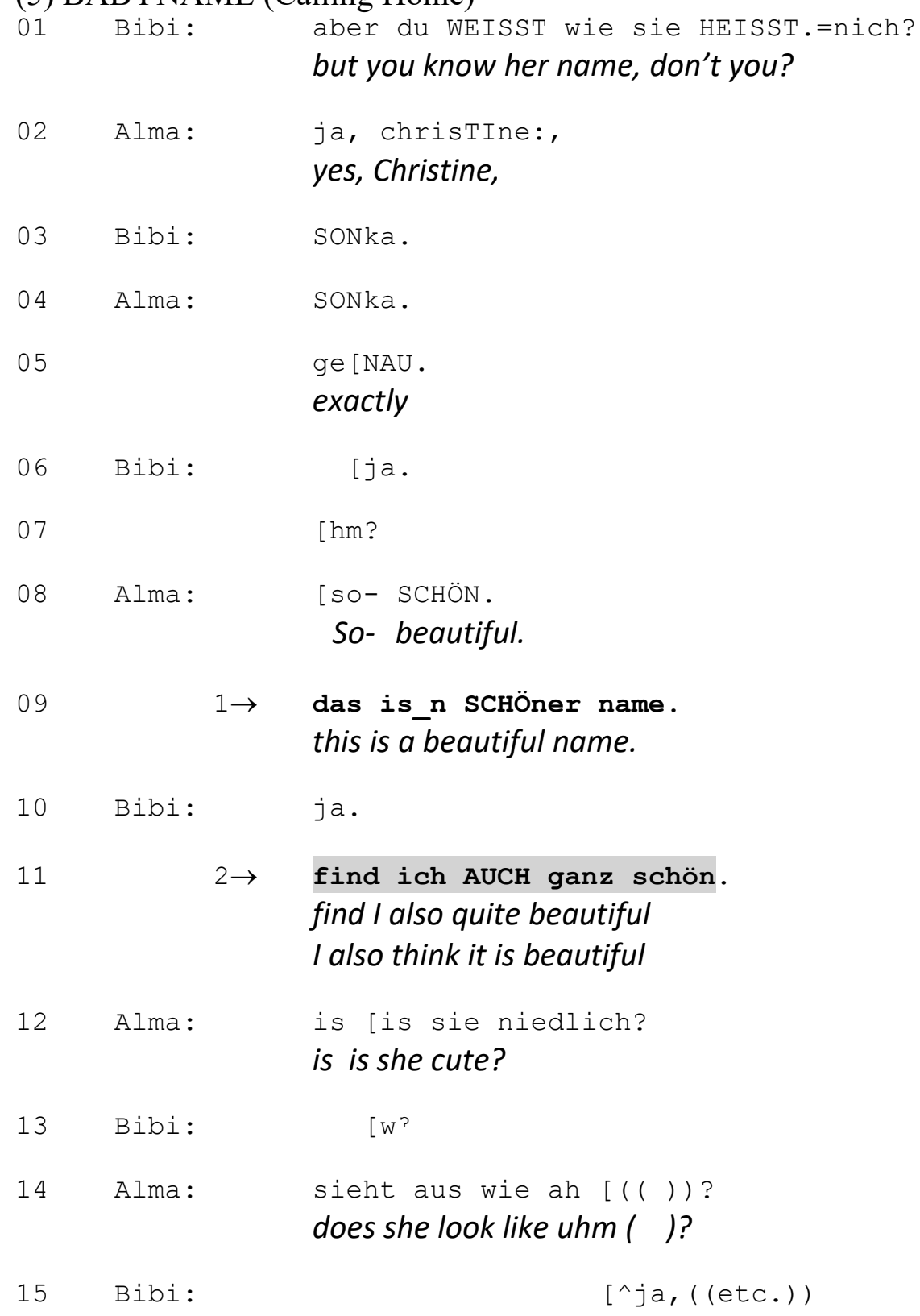

Bibi questions Alma's epistemic status by having her confirm that she knows the name of the baby (the negative question format implies that Alma should know it, but perhaps does not). Indeed, the name is produced by Alma somewhat tentatively in the following sequential slot (cf. the lengthening and upward intonation contour on Christine), and it turns out not to be correct. Bibi now displays her epistemic authority by telling Alma the right name: Sonka (1. 03). This creates the appropriate sequential position for Alma to evaluate the name in first position after a telling, which she does with some delay (1.08), i.e. after having secured the correctness of her understanding of the name. The assessment that is finally produced is a one-word TCU consisting of a simple evaluative adjective (schön, 1. 08). It is expanded into a full phrasal assessment without an opinion verb (09): Alma presents her assessment not as her own personal opinion but one that is shared by everybody. She upgrades it prosodically by putting the sentence stress on the adjective (das is_n SCHÖner name). After this delayed, but unhedged first assessment following Bibi's telling, the teller's own second assessment is clearly downgraded on the affiliative level: ganz schön 'quite beautiful' is less than schön 
'beautiful'. In addition, Bibi frames her second assessment as a personal opinion by using the finden-format, which further reduces the symmetry of commitment between the speakers.

Despite this display of low affiliation with the first assessor, Bibi uses a full opinion verb format for her second assessment (find ich AUCH ganz schön). Still, the assessment is formatted as a response: the anaphorical pronoun das in the position before the verb is 'dropped' (topic drop, see above), which is typical for responsive formats (Auer, 1993; cf. the alternative format das find ich AUCH ganz schön). The adverb auch 'also' links the second utterance to the first as well. So the speaker both relies on the previous first assessment and claims agency. After this second assessment with (moderately) upgraded agency but clearly downgraded affiliation, Alma (the first assessor and epistemically in the weaker position) opts for closing the assessment sequence and shifts to a new subtopic (enquiring after the looks of the baby, 1. 11).

The same pattern can be observed in excerpt (6). We are approaching the closing of a telephone conversation between Antje and Beate, after Beate has promised to pay Antje a visit:

(6) VISIT (Calling Home)

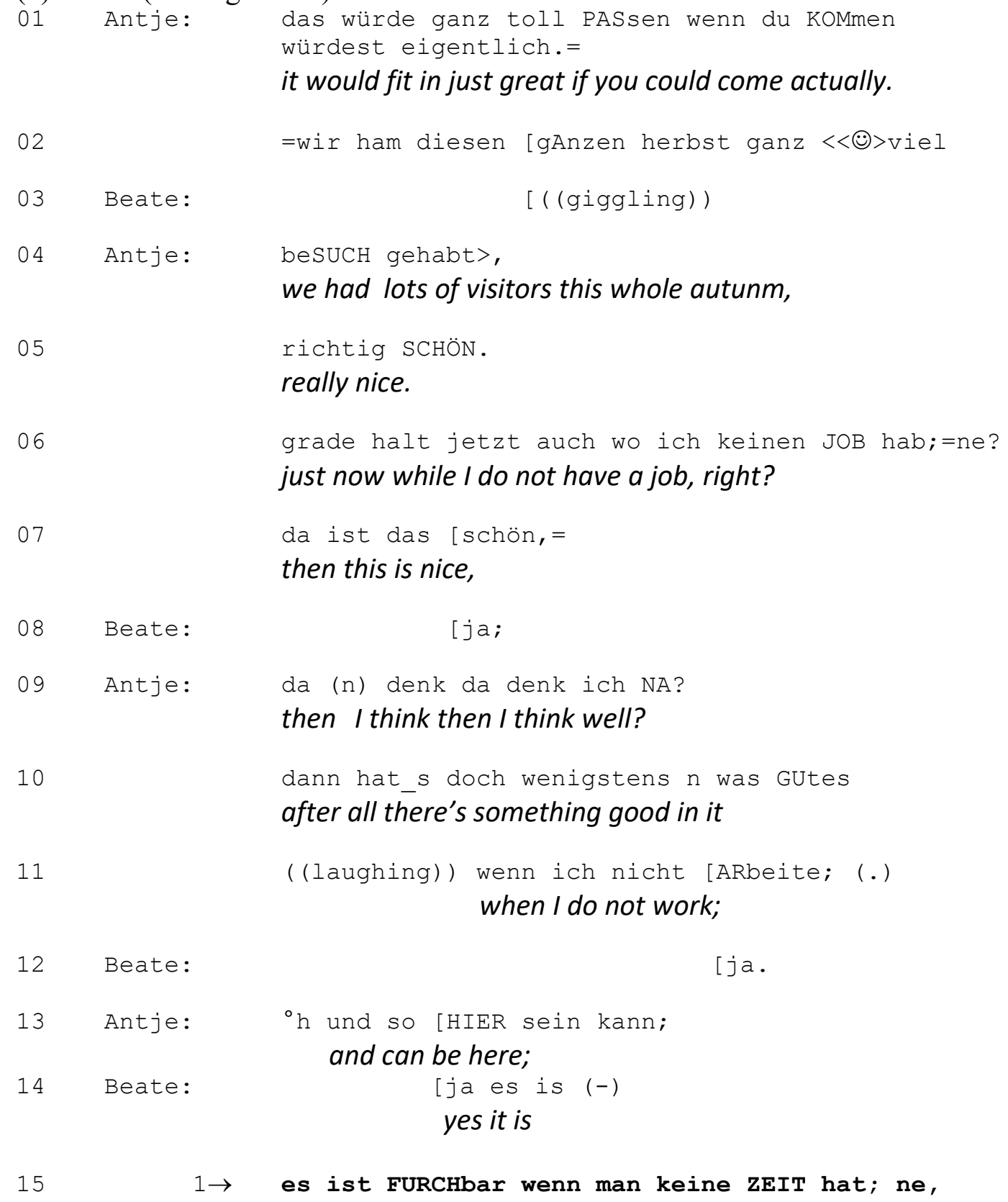




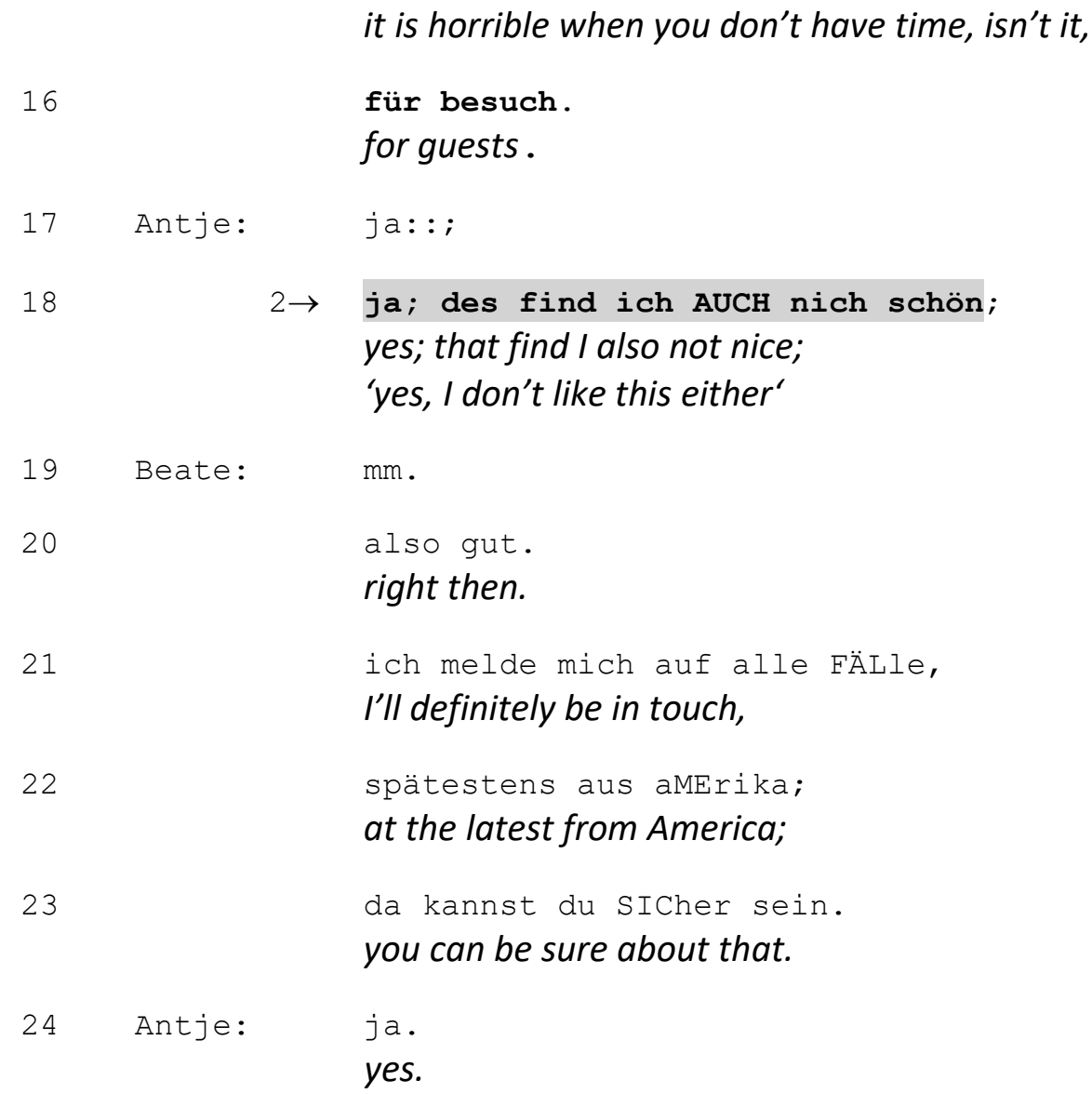

Antje is very enthusiastic about Beate's promise to pay her a visit, as she has a lot of time while she is unemployed. This, so she says, gives her at least a chance to spend time with her visitors (1. 01-12). Beate agrees and produces a first explicit assessment which summarizes (and "formulates") Antje's turn in a generalizing way, as a generally accepted opinion: it is horrible when you do not have enough time for your visitors (1. 14-15). Antje agrees. She does so first with two confirmation tokens (one of them emphatically lengthened) and then a second assessment (des find ich AUCH nich schön;). On the affiliative dimension, this second assessment is downgraded (from 'horrible' to 'not nice') and therefore not symmetrical. On the agency level, however, it is relatively strong. The speaker uses a full format with an evaluative adjective. The agency expressed through this format is even higher than in Antje's second assessment in excerpt (5), as the topic pronoun des is not 'dropped'.

Of course, the relationship between low agency/low affiliation and sequence closure is not deterministic. The formatting of the second assessment is only an invitation by the second assessor to close the sequence. The first assessor may choose to ignore this invitation and continue the assessment sequence. There can be good reasons to do so, as in (7), which is taken from an interview (MA1 and MA2, a married couple, are the interviewees). The interviewer has not known the interviewees previously.

(7) THE GOOD LIFE (DiALEKTINTONATION)

((MA1 and MA2 speak Mannheim dialect.))

01 MA1: =wonn isch on moi GESCHWISder denk; when I think of my brothers and sisters; 
hawwe wohl ä HAUS un schei EIgentumswohnung un

hawwe nix zum LEEw [e;

they have a house and a nice flat but have nothing to live on;

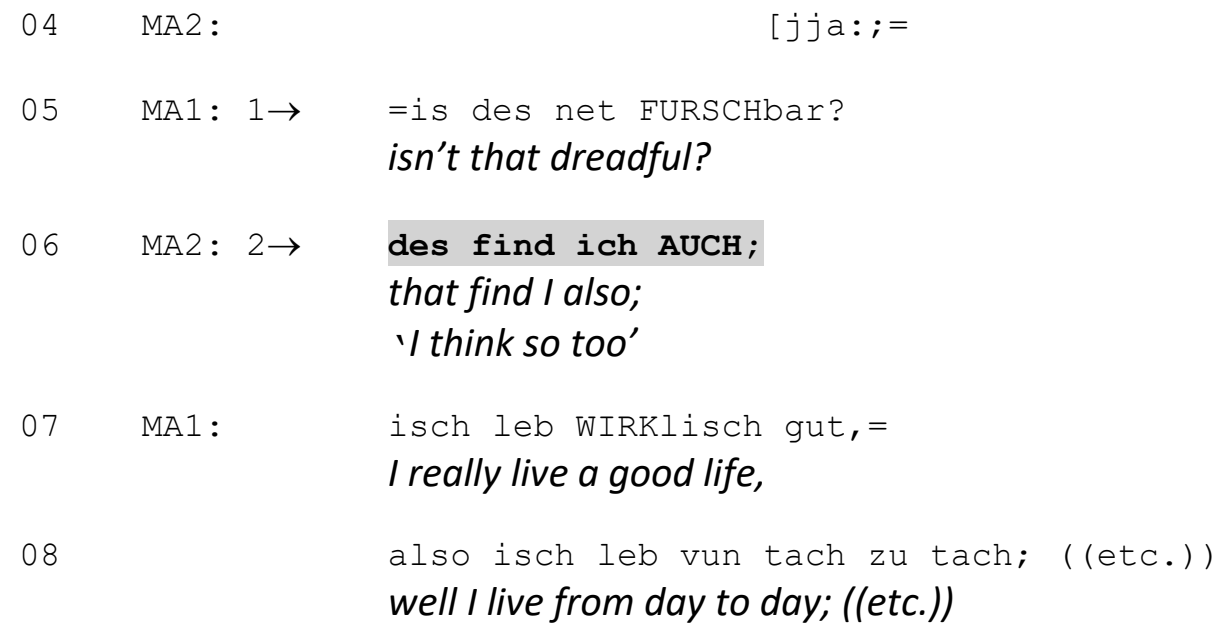

MA1 is the main speaker, his main addressee is the interviewer. He is about to compare his life with that of his brothers and sisters who (unlike himself) own 'a house and a nice flat' but have no money to live on. He ends the description of his brothers and sisters' situation with an assessment in the format of a leading question: 'isn't it dreadful'? This assessment is not responded to by the interviewer but by his wife, who aligns by producing a second assessment. The second assessment uses the reduced format which we already know from excerpt (3); it could therefore be heard as an invitation to close the sequence, i.e. with low agency and affiliation. However, MA1 expands the sequence. He continues by stating that his own life is a good life (for which he then gives examples). This expansion appears to contradict the pattern we have claimed to hold. But note that the participation frame in this case is very different from the examples considered so far: the two interviewees know each other well, and being an old couple, they doubtlessly also know each other's opinions. In a way, they act as co-tellers. The primary addressee for both of them is the interviewer, who, however, remains silent. For him, it may be difficult on epistemic grounds to produce a second assessment: he has no firsthand knowledge of the couple's social and economic situation (let alone that of their relatives). But not responding to an assessment often engenders an expansion of the sequence, in which first assessors will produce evidence for their evaluation. This is exactly what an interviewer wants - and so it happens. MA2's second assessment is not sufficient to close the sequence as she isn't its primary addressee.

\subsection{Sequence expansion: high(er) agency and no evaluative downgrading}

Let us now consider the opposite case of second assessments with high agency (hence no formal reduction and no analepsis) and an assessment of the same or even upgraded strength (i.e. with a relatively high level of affiliation). In this case, there is a tendency to expand the sequence, rather than to close it after the second assessment. A simple case of this found in extract (8):

(8) MASCARA (ZK)

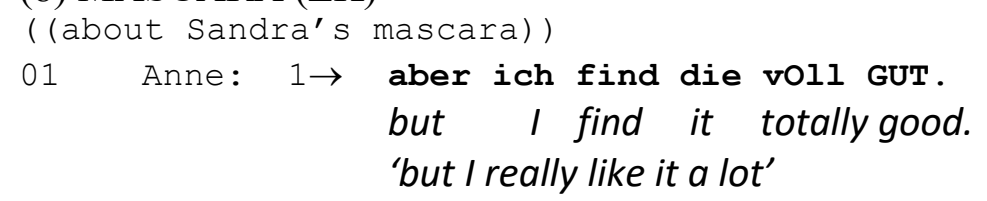




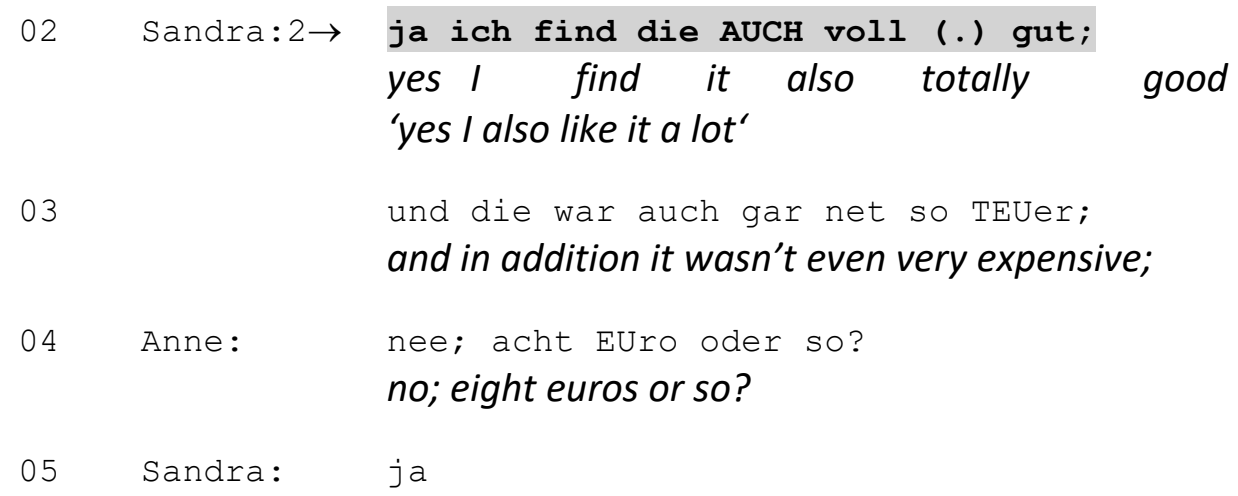

Anne produces a first assessment of Sandra's mascara using the finden-format and the strong evaluative expression voll gut. She can do this, as she produces an indirect compliment (the mascara belongs to Sandra who is also wearing it), in which case even a disagreeing second by the complimentee would not be a face-threatening act. Sandra in turn does not downgrade her second assessment but produces a second assessment which exactly repeats the structure and wording of the first. Although marked as a second by auch 'also', this assessment is produced as if it was a first otherwise, i.e. without analepsis (not even of the anaphoric pronoun). Compared to alternative formats for second assessments such as ich auch, find ich auch, or das find ich auch, the format chosen by Sandra presents her as an independent author of her words. As a consequence, the sequence is not closed immediately, but continues with details of the positive evaluation of the mascara (i.e. its low price).

The same link between the format chosen for the second assessment and the development of the sequence can be found in the following extract (9), from a conversation between three students. It includes four assessments of the same assessable. All but the first could be analeptic, i.e. produced without an explicit assessment term (such as in find ich auch), but none is. The topic is a particular series of children's books which the participants all enjoyed reading when they were children:

(9) THE FAMOUS FIVE (ZK)

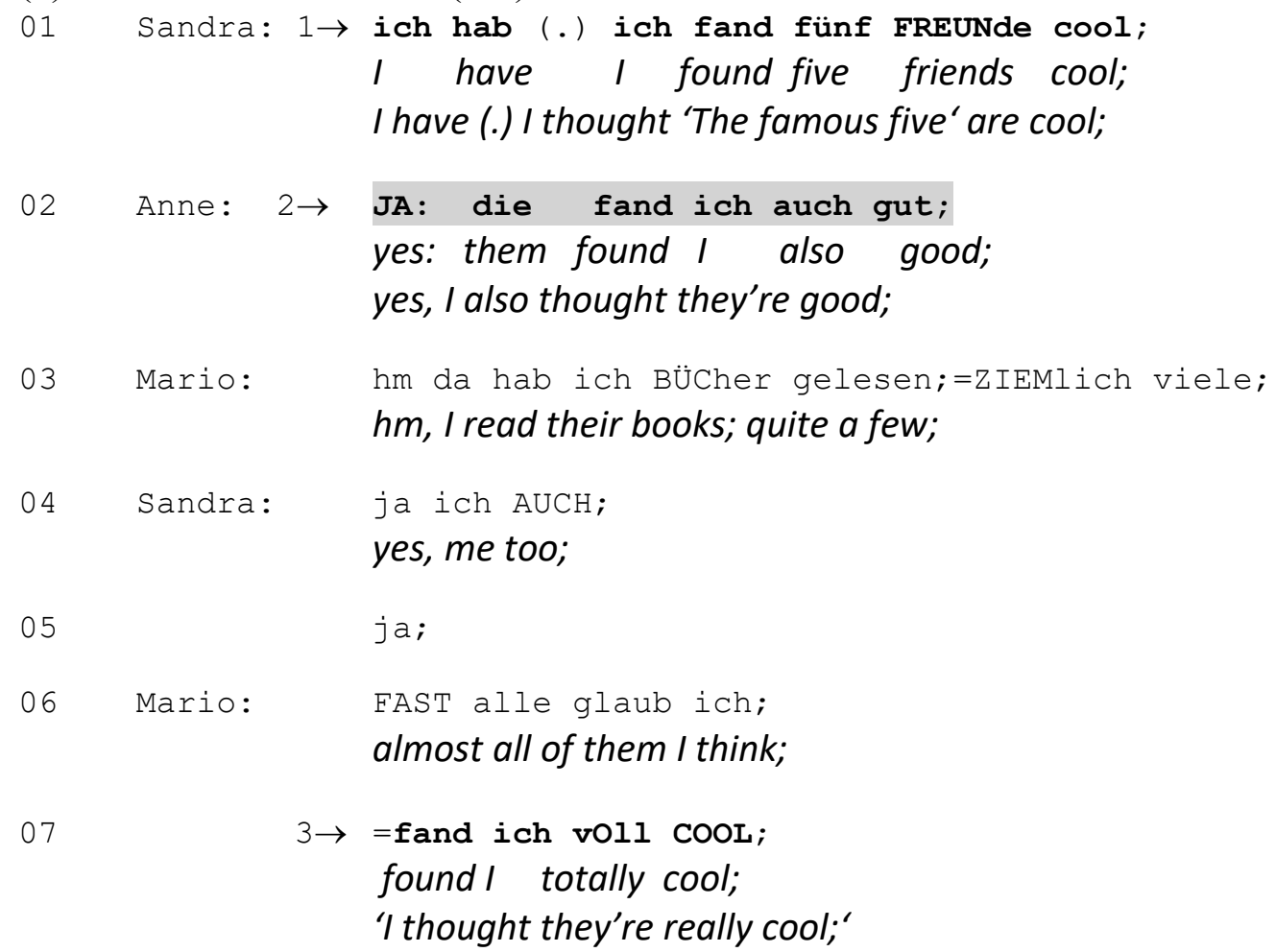




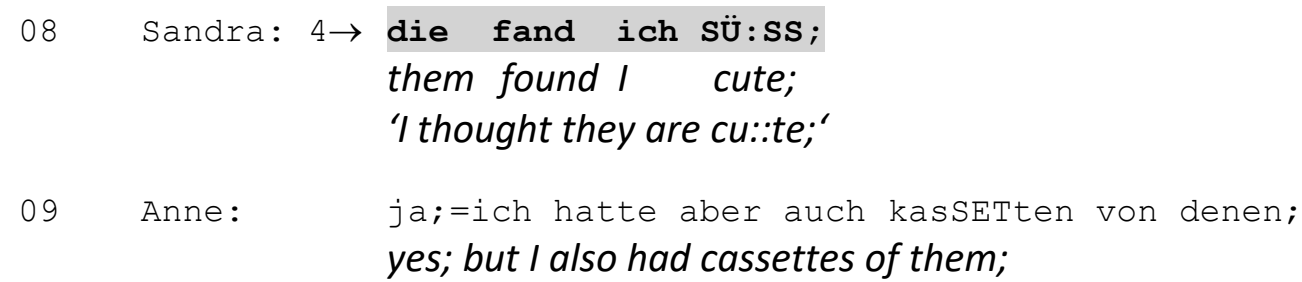

The first assessment of the Enid Blyton book series The Famous Five is still formulated in a cautious fashion by means of the finden opinion verb construction, and by using a moderately positive evaluative term, the adjective cool. Anne's second assessment copies the syntactic format without syntactic reduction; only the inversion of subject and object (now an anaphoric pronoun) and the adverb auch mark the second assessment as a second:

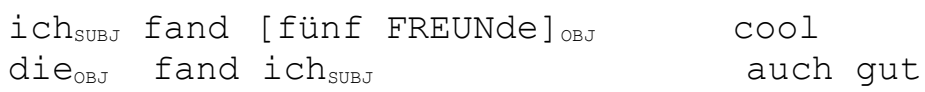

The assessment term cool is replaced by gut 'good'. Gut and cool are on the same level of evaluative strength (with cool gradually developing into the unmarked positive evaluative assessment adjective/adverb in the German of younger speakers), i.e. the second assessor affiliates with the first in being moderately positive as well. She displays agency and at the same time convergence with the previous assessment, contrasting with a low-agency/lowaffiliating second such as (fand) ich auch or fand ich auch nicht schlecht.

This second assessment does not end the sequence, however, although this is not immediately obvious in the next turn, which is produced by Mario. Mario so far hasn't taken part in the assessment sequence. He now takes the turn and states that he knows these books well (he has read almost all of them, 1. 03/05); Sandra aligns by saying that this holds for her, too (1. 04). Knowing the books (and having read most of them) is of course already an indirect indication of a certain enthusiasm for them. But it is only now that Mario produces a third assessment and thereby clearly expands the sequence. He re-uses the finden-format and Sandra's initial evaluative adjective cool, this time upgraded by an intensifying adverb: voll cool; the resumptive pronoun in topic position is omitted. To this, Sandra provides an equally strong fourth assessment, replacing voll cool by sü $\beta$ 'sweet' (with emphatic lengthening). This fourth assessment is less analeptic than the preceding third assessment, as a resumptive pronoun is used:

$$
\begin{aligned}
& \text { fand ich vOll COOL; } \\
& \text { die fand ich SÜ:B; }
\end{aligned}
$$

The format of this assessment underlines its independence from the preceding assessment and hence stresses the speaker's agency. At this point, the topic slightly shifts from 'The famous five' as books to their availability on cassettes, which are evaluated in the subsequent talk (not reproduced here in full).

As a third example, consider extract (10), from the same conversation. The topic are men who dye their hair.Mario, the only men in the group, is asked by Sandra in line 01 whether he would ever dye his hair.

(10) GREY HAIR (ZK)

01 Sandra: du wirst EH nie deine haare f̈̈rben nehm ich an;

you won't ever dye your hair anyway I suppose; 


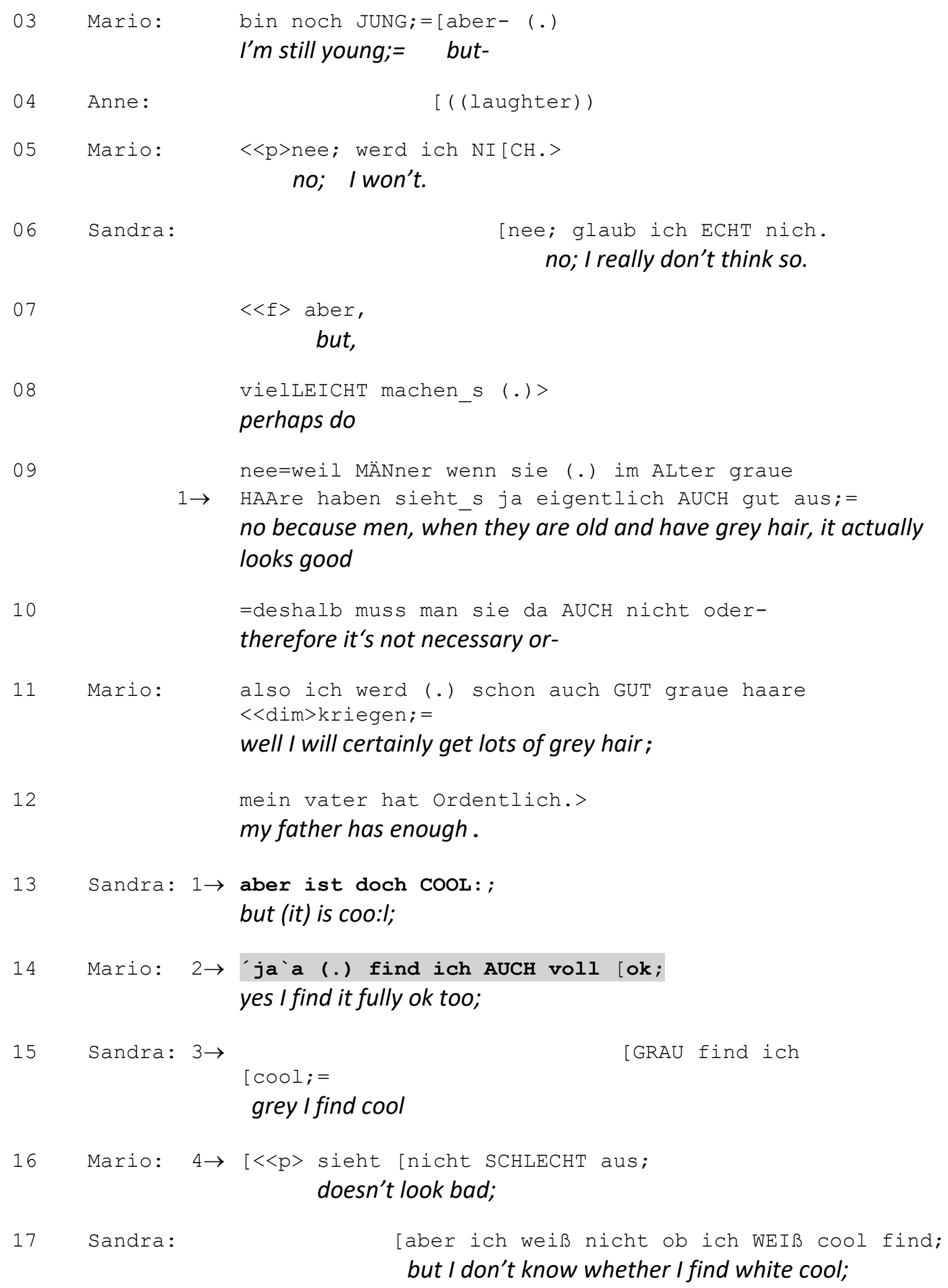

Sandra has talked about dyeing her hair before, and after some discussion of the pros and cons, she turns to Mario saying that he will probably never dye his hair (by implication: because he is a man). Mario hesitates a bit (03), but finally agrees (05). Perhaps due to this hesitation, Sandra adds that men do not have to dye their hair even when they get old, because grey hair looks good on them. Neither Mario nor Anne, the third participant, respond to this first assessment, as Sandra expands her turn and does not leave space to do so (10). Mario 
adds that dyeing his hair will probably become an issue for him when he is older, as his father already has lots of grey hair (11). Now Sandra repeats her first assessment in an upgraded format (13): the hedged eigentlich cool 'actually cool' becomes simply cool, the adjective is lengthened and therefore prosodically highlighted, and the particle doch indicates that this opinion is stated despite an actual or possible disagreeing opinion (which is implicit in Mario's turn). This upgraded, stand-alone assessment strongly invites a second assessment. Indeed, Mario produces such a second assessment (14). He uses the opinion verb finden and a full clausal format. The assessment term voll ok is roughly on the same level as cool, i.e. the two assessments are symmetrical. Given the full assessment format and the affiliation of the speakers, the sequence is expanded by both of them. Sandra in lines 15/17 concedes that white hair, in contrast to grey hair, would not be appreciated by her, and, in overlap,Mario adds another (now downgraded) assessment ('doesn't look bad', 16).

\section{Disagreeing second assessments}

Agency in a second assessment as expressed through syntactic formats tends to lose its relevance for the subsequent sequential development of the interactional exchange when it expresses disagreement. This is because disagreeing as such involves heightened agency: the second assessing speaker does not 'go along' with the first and, consequently, there is no mutual commitment to the same evaluative term (see Thompson et al., 2015, p. 186). Our data show that when a sequence contains a disagreeing second assessment, it is this lack of affiliation that is dealt with in the first place. This is manifest in accounts that regularly follow disagreeing second assessments, irrespective of the grammatical formatting of the assessing turn. Most of the overt disagreeing seconds occur in the Swedish data, which is a genrerelated fact: the participants of the group discussions are encouraged to express opinions and assessments, which occasionally leads to counter-positional arguing.

In the following sequence (11) from the Swedish group interview data the participants are once again assessing the (then) indie rock group Kent.

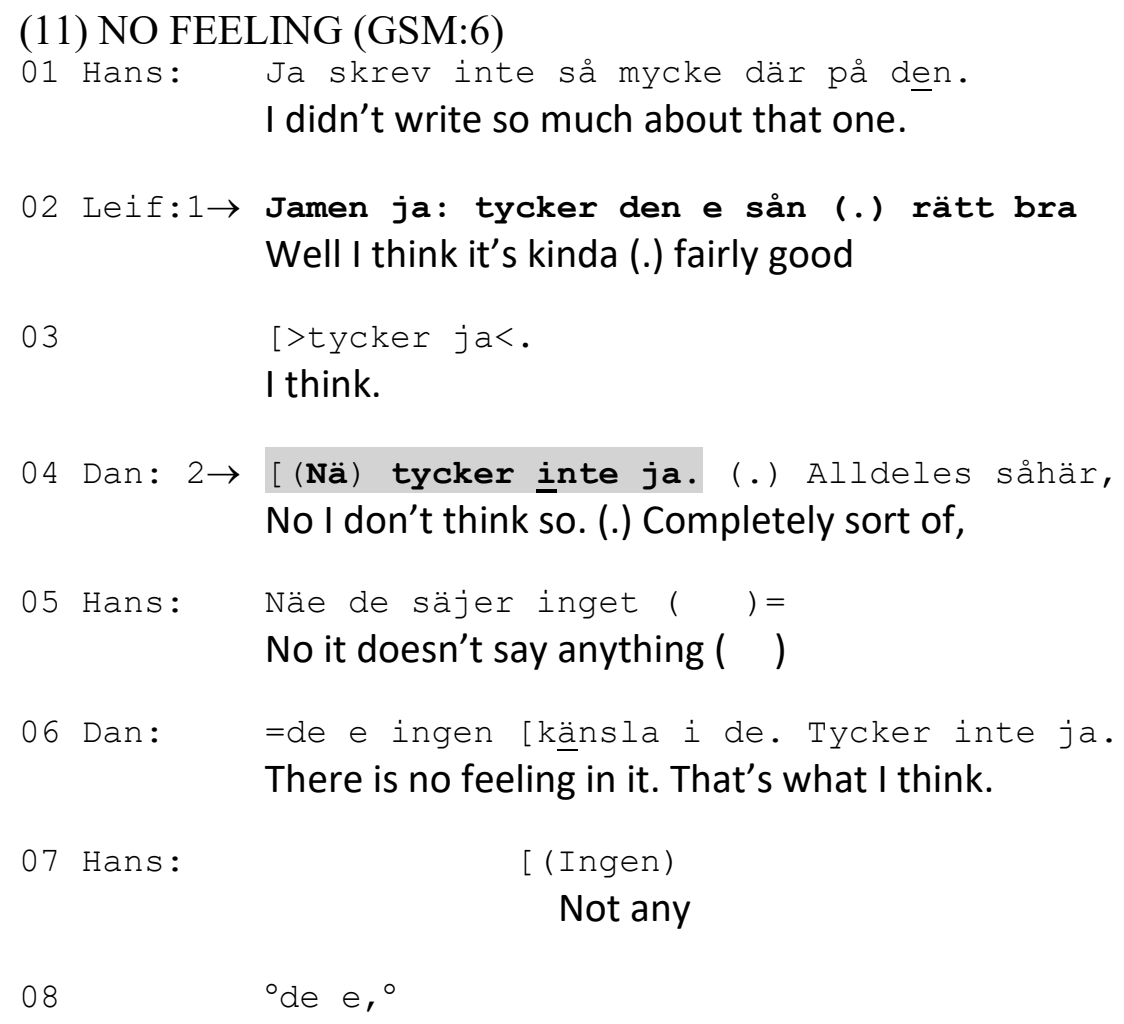


It is,

09 Dan: Näe.

Nope.

$10 \quad(0.3)$

11 Hans: .pt [Näe=

Nope

12 Dan: $\quad$ Inte de.

Not that one.

Hans initiates the sequence in line 01 with a turn that indicates indifference, i.e. he has not taken down many notes about the music sample (implying that he does not have much to say about it). The next speaker, Leif, gives a more explicit assessment in lines $02-03$, using the opinion verb tycka in a full bi-clausal pattern. The turn-initial particle jamen (lit. 'yes-but') indicates that this move somehow contrasts with the previous one, and the ensuing assessment is formulated somewhat hesitantly in moderately positive terms, rätt bra 'fairly good' This contribution is additionally modified, and thus doubly subjectified, by the turn-final stance marker tycker ja 'I think' (1. 03). Dan expresses bald disagreement in line 04: he initiates his turn in overlap with Leif's final turn-part, starting with the negation $n \ddot{a}$ 'no' and continues with a negated, mono-clausal tycka-construction. It is designed as back-tying through subjectverb inversion and absence of the clause-initial anaphoric de 'that'. The constructional patterns of the two opinion verb formats in (11) are shown below:

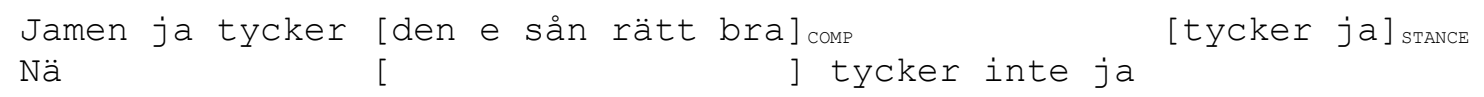

The responsive opinion verb construction tycker inte ja is compact and void of independently authored content apart from the negation. As shown in sections 4.1 and 4.2, such condensed assessment formats are implicative of sequence-closure in non-disagreeing second assessments. Here, however, the speaker continues by providing an account of what is wrong with the assessed music piece (1. 04-06). He ends the disagreeing turn with a disaffiliating stance marker, tycker inte ja (recycling the turn-initial opinion verb construction), that underscores his subjective take on the matter (the end of 1. 06). The negatively assessing participants Dan and Hans end the sequence with short turns confirming their negative stance $(1.9,11,12)$.

Extract (12) shows another sequence in which the second assessor disaffiliates with the preceding one, this time using a full syntactic format. The participants label the genre of the music sample they just have heard as singer-songwriter pop. Mia starts to characterize the music in line 03 as "typically Swedish", which, accompanied by a characteristic prosody, implies a negative stance. In line 06 she gives an explicit negative assessment, trå:kit svenskt 'boringly Swedish'. Both assessments are non-clausal, and do not use an opinion verb.

(12) BORINGLY SWEDISH (GSM:11)

01 Alex: Vispop?

Singer-songwriter pop?

02 Ben: Njao.=

Well yes.

03 Mia: =Typist svenskt. 
Typically Swedish.

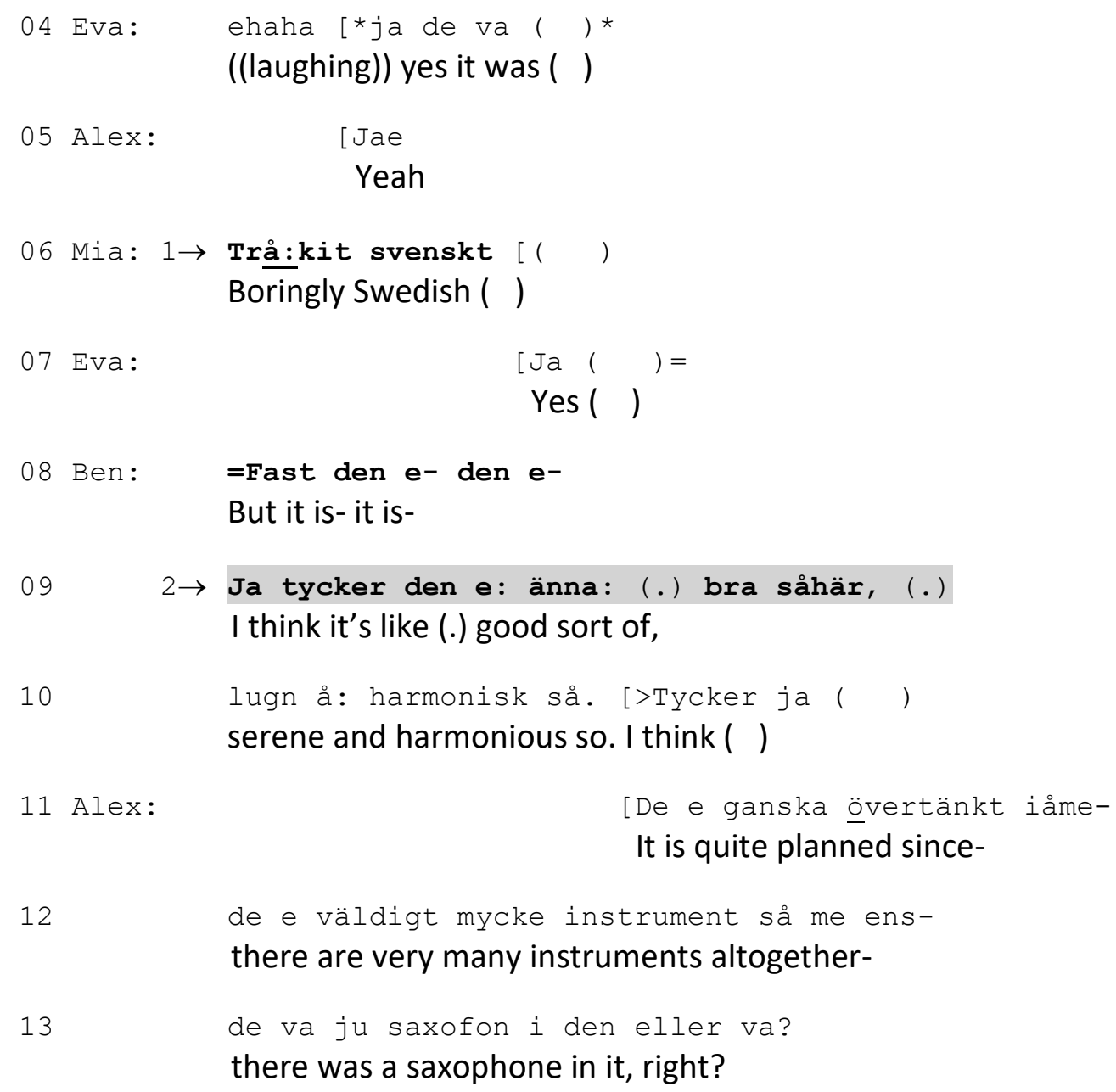

Ben begins to formulate a disagreeing counter-assessment in line 08: he starts with the conjunction fast 'but', which signifies a contrast, and continues with a pronoun-copula combination (den e 'it is') that projects a predicate, perhaps an evaluative adjective, but the evolving clausal unit is aborted twice. He then switches to the more subjective, bi-clausal opinion verb format that contains the positive term bra 'good'. This is produced with some prolonged sounds and pauses which may signal a dispreferred action; in addition, the hedges änna 'like' and såhär 'sort of' (1. 09) are used. This disagreeing counter-assessment is followed in line 10 by two descriptive adjectives that account for Ben's contrasting positive stand (the music is not boring but lugn a harmonisk 'serene and harmonious'). Finally, the turn ends with the subjective stance marker tycker $j a$ which recycles the opinion verb frame of the turn beginning (1. 10). Alex, in final overlap with Ben's turn, then takes the turn and starts to develop the topic in a different direction, moving away from the trouble-causing evaluation and focusing on details of instrumentation.

The second assessors in extracts (11) and (12) are clearly dealing with the delicacy of disagreeing and of committing themselves to a different evaluative term than the other. Even the bald disagreement in (11) is followed by an account, and this is also the case with the more hedged variant in (12). Both second assessments are framed by a subjective opinion verb construction (jag tycker/tycker jag) at the beginning and end of the assessing turns. Indeed, the group interview data show that subjective opinion verb formats are especially frequent in second assessments that disagree with an unmarked, non-subjectified first assessment (23 out of 32 disagreeing seconds), as in ex. (12). This tendency probably reflects what Fasulo and Monzoni (2009, p.374) found in their work on "subject-side assessments": 
they are "useful for downgrading and relativizing negative assessments". The opinion verb format contributes to this sense of downgrading because the evaluation is not presented as an indisputable fact, but restricted to the speaker's "sentiments".

As the extracts (11) and (12) show, both reduced and full opinion verb formats lead to sequence expansion after disagreeing second assessments. The expansion may account for the differences or redirect the topic away from the trouble cause. This suggests that the opposing projecting forces of the reduced vs. full assessment formats for the subsequent sequential development are neutralized in such interactional environments.

\section{Conclusion}

In experiencing the world, we also judge it; we try to tell things that are beneficial to us, that provide us with ease and comfort, from those that may threaten our immediate or future wellbeing, that are emotionally disturbing or simply unpleasant. Affects of this kind seem to be entirely personal and individual, based on one's biographical history and experience, and therefore deeply subjective. However, only few of these sentiments are physiologically determined; many of them are culturally mediated, and are shaped by the ways in which others experience the world. One of the ways (and perhaps the most important and efficient one) through which culturally shared sentiments are learned and transmitted, is language. Verbal expressions of sentiments through assessments are a very effective way to make them intersubjective in interaction with another. It is through assessments that a common evaluative understanding of the world becomes possible. In addition, assessing practices allow us to affiliate with others who share our evaluative stances and thereby lay the grounds for sociability, which is not only based on common knowledge, but also on shared values.

This study has identified a regular pattern for assessing sequences in German and Swedish conversation, focusing on the linguistic format of the "uptake" in second assessment position, i.e. a position in which the speaker's possibilities to deliver an independent assessment are strongly constrained. By choosing the syntactic form of their assessing turn, the second speaker occasions different sequential trajectories. Opinion verb constructions with a reduced (analeptic) and back-tying form are prone to close the assessing sequence, whereas grammatically fuller and non-pronominalized second assessments lead to more talk on the assessable. Both conversational parties can feel safe about what is being talked about is a topic, issue or object that they are sharing an evaluation about, and hence, which can be expanded and developed, and indeed, "celebrated" as a token of human connection (see Ford 2018).

This potential of the reduced and full formats to project different sequential trajectories relates to the speakers' agency constellations and their affiliation with one another. When they both use full clausal formats and lexically specified evaluative terms in the construction of their assessments, the first and second assessor are on symmetrical agency levels. By using structurally reduced second assessments, on the other hand, second speakers signal a lower level of agency. They take over the first assessor's evaluative term and therefore accept the first assessor's evaluation, but by doing so also weaken their commitment to this evaluation. As we have shown, lower commitment can also be signaled by downgraded second assessments, which are heard as disaffiliating and therefore as less encouraging to expand the assessment sequence.

Drawing on Schuetz, then, it can be argued that speakers of a language have intersubjective knowledge of the pragmatic implications of alternative opinion verb constructions, i.e. what courses of action a specific linguistic turn-format projects as a possible or probable next step; in our case sequence closure or expansion. While signaling lower or higher agency/affiliation, speakers project actions in a "typical", or systematic, way, 
i.e. in a manner that is recognizable to the other and which therefore has the protential of bringing about "the state of affairs aimed at" (Schuetz, 1953, p. 20), thus producing intersubjective behavior.

\section{References}

Auer, Peter (1993). Zur Verbspitzenstellung im Gesprochenen Deutsch. Deutsche Sprache 3, 193-222.

Auer, Peter (2014). Sentences and their symbiotic guests: Notes on analepsis from the perspective of online syntax. Pragmatics 24(3), 533-560.

Auer, Peter (2015). The temporality of language in interaction: Projection and latency. In A. Deppermann, \& S. Günthner (Eds.), Temporality in Interaction (pp. 27-56). Amsterdam: Benjamins.

Auer, Peter, \& Lindström, Jan (2016). Left/right asymmetries and the grammar of pre- vs. postpositioning in German and Swedish talk-in-interaction. Language Sciences 56, 68 92.

Auer, Peter, \& Uhmann, Susanne (1982). Aspekte der konversationellen Organisation von Bewertungen. Deutsche Sprache 1, 1-32.

Clift, Rebecca (2001). Meaning in interaction: The case of actually. Language 77(2), 245291.

Couper-Kuhlen, Elizabeth, \& Selting, Margret (2018). Interactional linguistics: Studying language in social interaction. Cambridge: Cambridge University Press.

Couper-Kuhlen, Elizabeth \& Thompson, Sandra (2000). Concessive patterns in conversation. In E. Couper-Kuhlen, \& B. Kortmann (Eds.), Cause, condition, concession, contrast (pp. 381-410). Berlin: de Gruyter.

Enfield, Nick J. (2011). Sources of asymmetry in human interaction: Enchrony, status, knowledge, and agency. In T. Stivers, L. Mondada, \& J. Steensig (Eds.), The morality of knowledge in conversation (pp. 285-312). Cambridge: Cambridge University Press.

Fasulo Alessandra, \& Monzoni, Chiara (2009). Assessing mutable objects: A multimodal analysis. Research on Language and Social Interaction, 42(4), 36-376.

Heritage, John, \& Raymond, Geoffrey (2005). The terms of agreement: Indexing epistemic authority and subordination in assessment sequences. Social Psychology Quarterly 68, $15-38$.

Ford, Cecilia C. (2018). Celebrating joyful connection. In D. Favareau (Ed.), Co-operative engagements in intertwined semiosis: Essays in honour of Charles Goodwin (pp. 125135). Tartu: University of Tartu Press.

Lindström, Jan, \& Karlsson, Susanna (2005). Verb-first constructions as a syntactic and functional resource in (spoken) Swedish. Nordic Journal of Linguistics 28(1), 1-35.

Mullan, Kerry (2010). Expressing opinions in French and Australian English discourse. Amsterdam/Philadelphia: Benjamins.

Mörnsjö, Maria (2002). V1 declaratives in spoken Swedish. Lund: Lund University.

Norrby, Catrin, \& Wirdenäs, Karolina (1998). The language and music worlds of high school students. In I.-L. Pedersen, \& J. Scheuer (Eds.), Sprog, køn-og kommunikation (pp. 155-163). Copenhagen: Reitzel.

Ochs, Elinor, Schegloff, Emanuel A., \& Thompson, Sandra A. (1996). Interaction and grammar. Cambridge: Cambridge University Press.

Ogden, Richard (2006). Phonetics and social action in agreements and disagreements. Journal of Pragmatics, 38, 1752-1775. 
Pomerantz, Anita (1984). Agreeing and disagreeing with assessments: Some features of preferred/dispreferred turn shapes. In J. M. Atkinson, \& J. Heritage (Eds.), Structures of social action (pp. 57-101). Cambridge: Cambridge University Press.

Schegloff, Emanuel A. (1996). Turn organization: One intersection of grammar and interaction. In E. Ochs, E. A. Schegloff, \& S. A. Thompson (Eds.), Interaction and grammar (pp. 52-133. Cambridge: Cambridge University Press.

Schuetz, Alfred (1953). Common sense and the scientific interpretation of human action. Philosophy and Phenomenological Research, 14(1), 1-38.

Selting, Margret et al. (2009). Gesprächsanalytisches Transkriptionssystem 2 (GAT 2)

Gesprächsforschung 10 (http://www.gespraechsforschungozs.de/heft2009/heft2009.htm), 353-402.

English adaptation: A system for transcribing talk in interaction: GAT 2 translated and adapted for English by Elizabeth Couper-Kuhlen and Dagmar Barth-Weingarten.

Gesprächsforschung 12 (2011), 1-51.

(http://www.gespraechsforschung-ozs.de/fileadmin/dateien/heft2011/px-gat2englisch.pdf)

Thompson, Sandra A., Fox, Barbara A., \& Couper-Kuhlen, Elizabeth (2015). Grammar in everyday talk: Building responsive actions. Cambridge: Cambridge University Press.

Trutkowski, Ewa (2016). Topic drop and null subjects in German. Berlin: de Gruyter. 